\title{
The MDG Paradigm, Productive Capacities and the Future of Poverty Reduction
}

\author{
Charles Gore
}

Abstract The MDGs are important as they have led to a new international development consensus. However, this consensus has not effectively reduced poverty as it is based on a 'Faustian bargain', in which international commitment to promoting economic development and reducing global income inequality has evaporated, and national and international policies have focused on promoting global integration rather than production and employment. It is necessary now to build a new consensus around global sustainable development and a new policy narrative founded on the development of productive capacities and on rebalancing the terms of development partnership.

\section{The nature of the MDG paradigm}

The Millennium Declaration adopted by the General Assembly of the United Nations in September 2000 states that 'in addition to our separate responsibilities to our individual societies, we have a collective responsibility to uphold the principles of human dignity, equality and equity at the global level' (UN 2000: para 2). This commitment has been translated into practice through the adoption of the Millennium Development Goals (MDGs) as a focus for international and national development policy. One may quibble with the precise selection of these Targets and Indicators. But the MDGs are immensely significant.

At the simplest level, they are part of the emergence of a global consciousness in which persons all over the world are seen as living in a single social space and the nature of their wellbeing is compared. But beyond this, the MDGs have provided the basis for a new international development consensus during the present decade. International development cooperation in the 1960s and 1970s was founded on a Keynesian development consensus in which economic development in the South increased the import capacity in developing countries, which in turn supported the achievement of full employment in the North. At the beginning of the 1980 s, low inflation replaced full employment as the central objective in the North, and this old international development consensus, which was based on mutual economic interests, broke down. The MDGs, stiffened by commentaries which link global poverty to global insecurity, terrorism and public health scares, have provided a common ground on which a new international development consensus has been forged.

But for developing countries, this new international development consensus was based on a 'Faustian bargain'. That is to say, the benefits of the new consensus were achieved at the cost of a major sacrifice.

The 'Faustian bargain' arises because the introduction of global goals inevitably requires a purposive rather than procedural conception of international society. With their joint commitment to achieve the MDGs, members of the international community exist as an association of States joined together in a cooperative venture to promote common ends. This is far different from a procedural conception of international society which consists of an association of States joined together through their common respect for a set of rules, 
norms and standard practices which govern the relationships between them. In the purposive conception of international society, outcomes matter and international relationships are instrumentally valuable for achieving these outcomes. In the procedural conception, rules and standard practices of international conduct set certain restrictions and restraints on how States may pursue their own distinct and different purposes. These rules and practices are intrinsically important, no matter what the outcomes (Nardin 1983: Ch. 1).

But the problem facing any attempt to implement a purposive conception of international society is to find common ground on common purposes. Those wedded to the procedural view of international society, who argue, for example, that creating a 'level playingfield' between players with radically different resources and capabilities is a sufficient condition for global social justice, are reluctant to constrain States in the purposes which they pursue. The 'Faustian bargain' underlying the MDGs involves, on the one hand, a recognition that outcomes matter, but on the other hand - and this was the sacrifice - very strict limits on the types of outcome that mattered. Indeed there were two major shifts away from the types of outcome which mattered in the earlier international development consensus of the 1960s and 1970s.

First, there was a shift away from the development of national economies to a focus on the nature of individuals' lives. The accelerated economic growth targets of the First and Second United Nations Development Decades (the 1960s and 1970s), which were partly intended to close the inequality gap between industrial countries and developing countries and were based on comparisons between countries, were thus replaced by poverty and human development targets.

Second, there was a shift from a maximal future horizon in which development meant catching up with the living standards of the richest countries to future targets in which certain minimum standards of decent living should be achieved by a certain point in time. This minimalist approach is apparent, for example, in the MDG Target of reducing the proportion of people living on less than $\$ 1$-a-day by half, by 2015 . This identifies the typical standard of minimally adequate consumption in the poorest countries in the world as the global standard of poverty eradication. But it would be equally valid, and also more ethically defensible, to adopt the typical standard of minimally adequate consumption in the richest countries as the global standard. With globalisation, individual expectations are rising all over the world to the standards of living in the rich countries. Logically, therefore, one appropriate standard for poverty would be the poverty line in Organisation for Economic Co-operation and Development (OECD) countries, which has been estimated as $\$ 15$-a-day (Pritchett 2003), not $\$ 1$-a-day, which was estimated on the basis of the average level of the national poverty lines of the poorest countries.

To put it bluntly, the new international development consensus has been achieved through the elimination of the old idea of promoting national economic development. The MDGs are universally called Millennium Development Goals. But in practice, there is nothing developmental about the MDGs apart from the fact that the poverty and human development outcomes should be achieved in 'developing' countries. International commitment to promoting economic development and reducing international income inequality has quite simply evaporated. Moreover, the concern for processes of evolution and transformation has been replaced with preoccupation with auditing standards of evaluation and performance.

\section{Elements of the current MDG paradigm}

As a set of indicators, the MDGs in themselves do not constitute a policy paradigm. These indicators could be embedded within a variety of national development strategies (see Gore 2005) and also within different forms of international development cooperation. However, it is possible to speak of the current MDG paradigm because the MDGs have become the cornerstone of a particular approach to development and poverty reduction during the current decade. This includes an approach to international development cooperation as well as an analytical and policy narrative about how to promote development and poverty reduction at the national level. These two elements are in fact the institutional realisation of the new international development consensus.

The approach to international cooperation stems from the OECD/DAC 1996 report, Shaping the 21st 
Figure 1 Trends in poverty and child mortality in LDCs: actual and MDG-compatible incidence, 1980-2005

Absolute poverty incidence in the LDCs, 1980-2005

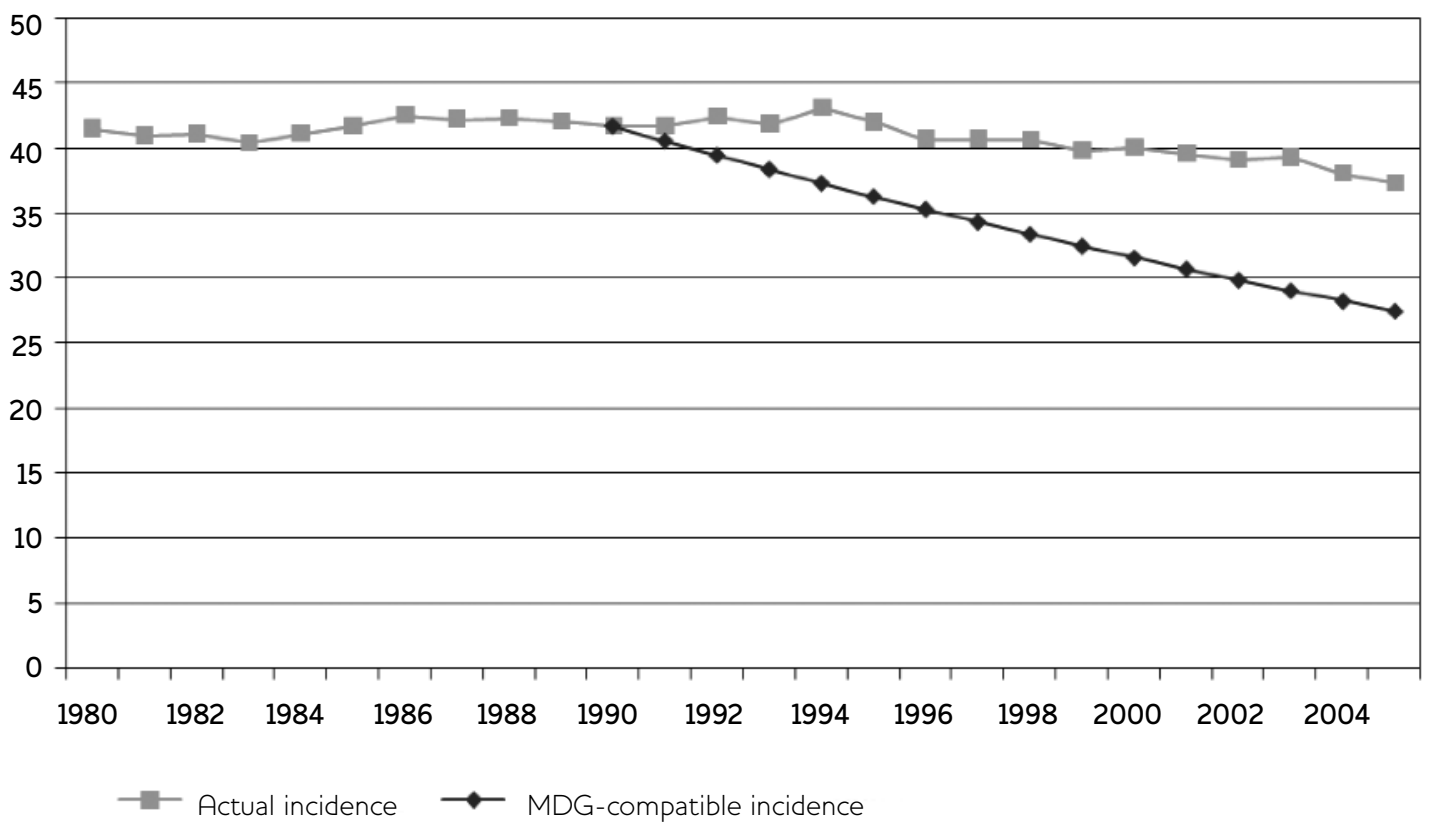

Child mortality incidence in the LDCs, 1980-2005

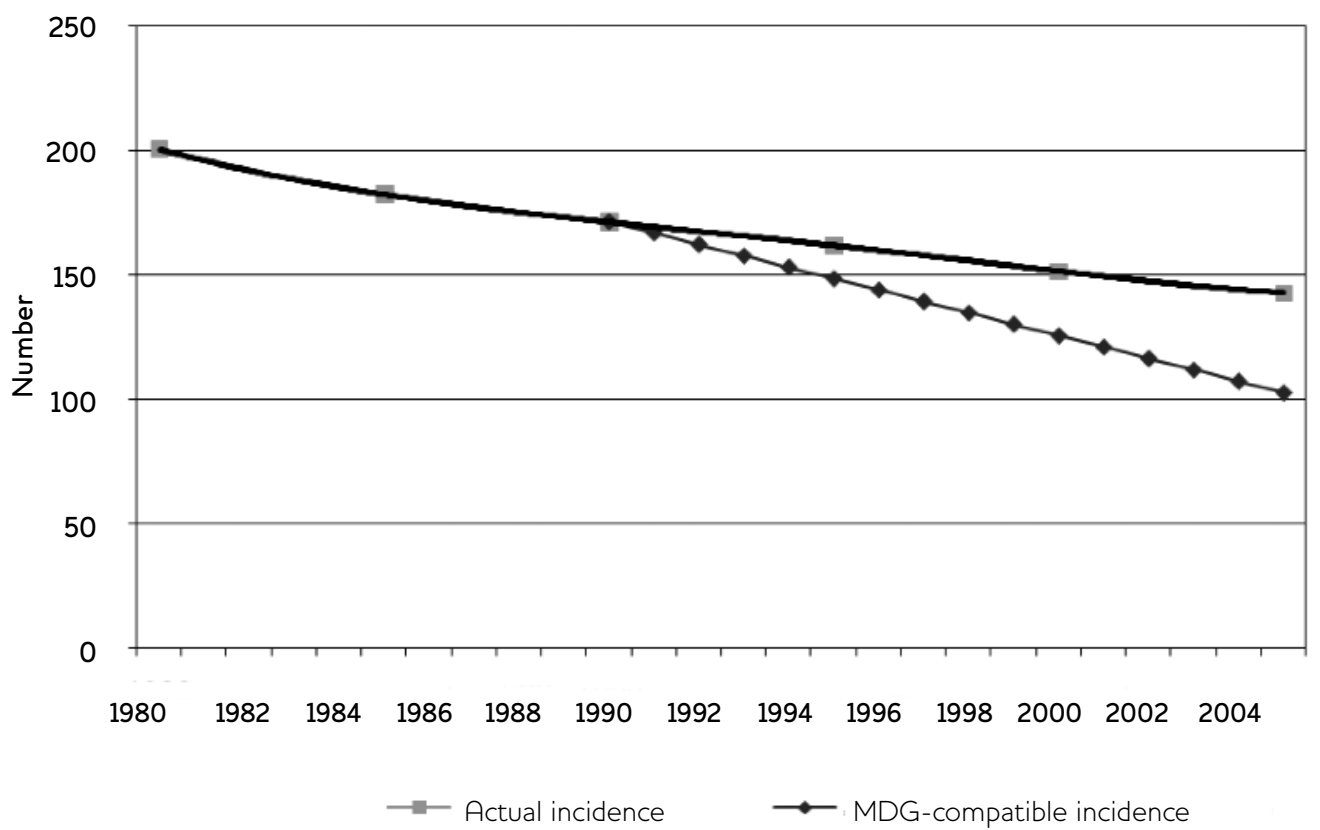

Note The MDG-compatible incidence is the hypothetical path that poverty and child mortality incidence would need to follow if the LDCs were to achieve the respective MDG Targets by 2015. 
Century: The Contribution of Development Cooperation. This important report argued for a new approach to development cooperation which: (1) focused on specific poverty and human development goals expressed in seven International Development Targets (IDTs); (2) adopted a partnership approach in which donors' aid was closely harmonised and aligned with the nationally owned strategies of recipient countries, and (3) used a broad range of instruments going beyond traditional financial and technical assistance including, for example, market access concessions and the encouragement of private capital flows. This approach has been operationalised over the last ten years as the IDTs were transformed and extended into the MDGs in the wake of the Millennium Declaration, the Poverty Reduction Strategy Paper (PRSP) was introduced and diffused as a national governance mechanism for achieving global goals, and an aidplus approach to development partnership was endorsed in the Monterrey Consensus. The MDGs have also become the key targets in the increasingly complex application of results-based new public management to improve aid effectiveness via the Paris Declaration process.

The analytical and policy narrative of the current paradigm argues that the best national strategy for achieving poverty reduction is 'global integration with a human face'. That is to say, national policies should promote close integration with the global economy through deep liberalisation, both at and behind national borders, and through harmonisation with global standards. This narrative was first propagated as the best policy for developing countries with the introduction of structural adjustment programmes of stabilisation, liberalisation and privatisation in the early 1980s. As globalisation was identified as a key driver of change in the 1990s, this package of policies, which came to be known as the Washington Consensus, was increasingly advocated as the best way for countries to maximise the benefits of globalisation (e.g. by attracting FDI, private capital inflows and dynamic external sources of demand through exporting) as well as to minimise the risks of being left out. However, following the publication of UNICEF's Adjustment with a Human Face in 1987 and with the increasing moral pressure from the information on human development deficits disseminated through UNDP's Human Development Report throughout the 1990s, there have been increasing efforts to add a social dimension to the process of global integration (see Gore 2000).

The MDGs represent the full flowering of this inflection towards global integration with a human face in the present decade. They are thus not a standalone product. Within the current paradigm, they work as the human face of the narrative of global integration. This is an expanded version of the Washington Consensus which, although pronounced dead on many occasions in the last ten years, still enjoys a lively after-life. In one interpretation, the social standards which MDGs embody should both result from, and facilitate, the process of integration. However, more realistically, the MDGs can be understood as a minimum social floor which policymakers should strive to achieve while they are implementing policies whose primary goal is liberalisation and global integration.

\section{The impact of the MDG paradigm on poverty reduction: the case of the least developed countries}

The effectiveness of the current MDG paradigm on poverty reduction depends on the working of the 'Faustian bargain', and the effectiveness of the new approach to development cooperation and the strategy of 'global integration with a human face'. Drawing on UNCTAD (2008), we examine what is happening in the least developed countries (LDCs).

The available evidence indicates that although some LDCs are making significant progress towards achieving some MDG Targets, there are very few LDGs that are making progress on a broad front. Most progress is being made on targets which depend primarily on the level of public service provision. Progress in increasing primary school enrolment in purely quantitative terms has been most significant, with improvements in access to water, and then sanitation, lagging behind owing to lower prioritisation and greater costs. Progress towards targets such as extreme poverty and hunger, that depend more on household incomes than on public service provision, has been slowest. It has also proved difficult to maintain progress in reducing child mortality, where trends reflect the effects of both private incomes and public services.

Figure 1 shows trends in the incidence of $\$ 1$-aday poverty and child mortality for the LDGs as a 
group from the early 1980 s until 2005 . The LDCs as a group are off-target to meet the Goal of halving the incidence of $\$ 1$-a-day poverty by 2015. This decreased from a peak of 44 per cent in 1994 to just 36 per cent in 2005. If the current MDG paradigm were making a difference to poverty reduction, one would expect a significant improvement in poverty reduction performance after 2000. There is, indeed, a break in the trend but this occurred in 1994, not in 2000. For child mortality, the rate of decline is similarly very slow and the LDCs as a group are off-target to meet the Goal of reducing child mortality by twothirds by 2015 . No real change in the trend is discernable in 2000.

These trends, which will certainly be adversely affected by the impact of the global financial crisis, can be attributed to the inadequacy of the MDG paradigm.

As a national strategy, global integration with a human face simply does not address the major structural weaknesses of LDCs. Most of them face an intensifying employment problem in which they cannot generate sufficient productive jobs and livelihoods for the rapidly expanding population of working age. The present and future scale of the employment challenge is worth underlining. In Mali, for example, the new entrants to the labour force were 171,800 in 2005 and they will increase every year to a peak of 447,800 in 2045, when the annual additional labour force will start to decline. In Madagascar, the new entrants to the labour force in 2005 are estimated as 286,200 and their number will increase every year to a peak of 473,400 in 2035, when the annual additional labour force will start to decline (Losch et al. 2008). The employment problem is also exacerbated because at the same time as the numbers of new entrants to the labour force are growing, more and more people are seeking work outside agriculture. The capacity of agriculture to absorb new entrants to labour markets is diminishing as land availability, land quality and average farm size decline, and this will be aggravated by climate change. There is now accelerating urbanisation without industrialisation. Yet the booming services sector mainly consists of low-productivity informal activities such as petty trade.

This permanent employment crisis is the root cause of the LDC's persistent poverty problem. It is difficult to envisage how the MDGs can be achieved on a sustainable basis when countries are going through a blocked structural transformation. Rapid and deep trade liberalisation has been undertaken in two-thirds of the LDCs, particularly in Africa, and is further complicating this task. Food imports have been rising significantly and LDC governments must now somehow increase agricultural productivity, and at a time when the growing demand in their urban centres is increasingly supplied from abroad. At the same time, they must generate productive off-farm employment in industry and services, while facing global competition.

Gurrent national policies are not right to address these challenges.

The partnership approach to development cooperation has also been flawed. Implicit within it is the idea that aid works best when based on a genuine and balanced partnership of equals. But it is reasonable to ask: what are the terms of development partnership between donor and recipient countries when there are major inequalities between them in terms of resources, capabilities and power?

The evidence from the LDCs shows that, despite efforts to the contrary, country ownership continues to be undermined. This is not simply due to the non-alignment of aid with national strategies, although this still matters. It also reflects: (1) weak technical capacities coupled with strong incentives for recipients to anticipate and internalise donor priorities in policy formulation; and (2) the prioritisation of donor agendas in policy implementation through the working of policy conditionality, administrative guidance via monitoring indicators and selectivity in donor financing choices. At worst, LDC governments are placed in a double-bind in which they are committed to achieve global development Goals through the adoption of national development measures which make their achievement impossible (Gore 2004). In practice, most second-generation PRSPs in the LDCs are so broadly defined and so weakly embedded in a strategic choice that there is an ownership frontier within the PRSP. Part of the policy agenda is strongly owned by national Governments; part is strongly owned by donors; and in between there is a shifting zone of consensus policies (see UNCTAD 2008). Aid which is aligned with the national strategy tends 
to be aligned with the donor-driven part of the policy agenda.

Another problem is that donors are taking a sectoral approach to MDGs, focusing on, e.g. basic health, or primary education, or water, or even a favourite disease. With this approach, it is possible selectively to achieve targets but this does not add up to comprehensive progress. Instead there are dysfunctional outcomes, for example, when more and more children go through school but public expenditure cannot increase sufficiently to hire extra teachers and so quality falls. Or they go through school but then cannot find jobs or productive livelihoods. In the end, achieving the MDGs will require a combination of rising private incomes (based on productive employment) as well as improved access to public services (for education, health, water, sanitation). However, aid to LDGs is concentrated more and more on social sectors and less on production. Indeed, the share of aid commitments to production sectors (including agriculture) and economic infrastructure fell from 48 per cent in the period 1992-4 to 25 per cent in 2006 (UNCTAD 2008).

Finally, turning to other aspects of the international development cooperation which are complementary to financial and technical assistance, it is clear that there are major gaps in the partnership approach (Gore 2003). In this regard, it is notable that the nature of an international commodity policy has been right off the policy agenda, although there is a close link between differences in the incidence of extreme poverty among LDCs and their degree of commodity dependence (UNCTAD 2002). Moreover, there are no major initiatives to support LDCs in relation to technological transfer and learning, although this is critical for the process of structural transformation and diversification, even though the TRIPs agreement expressly urges the adoption of special measures for LDGs to this effect.

\section{Elements of a new development paradigm}

In the next few years, the significant negative economic and social consequences of the global financial crisis in most developing countries may actually reinforce the importance of the MDGs. Progress towards their achievement will be used as a litmus test of social protection measures which are put in place to mitigate the impact of the crisis on poor people. But the financial crisis is such a major and global event that it should properly be understood as a 'crisis of globalization' (Ferguson 2009) which marks the end of an era of development.

Business as usual is not a viable option now. What is required over the coming years is not tinkering to increase the effectiveness of poverty reduction efforts. Rather, there is a need for a new international development consensus; a new analytical and policy narrative about how development can be promoted; and a new approach to international development cooperation.

\subsection{The nature of a new international development consensus}

The new international development consensus should build on the key achievement of the current MDG consensus, which is to initiate a purposive conception of international society which recognises that global developmental outcomes matter. However, it is necessary to go much further in terms of what outcomes matter.

The most critical challenge now is to find effective and fair ways of mitigating and adapting to climate change while at the same time reducing global income inequalities and facilitating the realisation of the development aspirations of billions of people in developing countries. The scientific evidence is increasingly showing that major public action is required now to mitigate climate change if we are to avoid catastrophic and irreversible changes. However, this action must not block economic development. Milanovic (2005) shows that we live in a world in which the richest 1 per cent of people in the world receive as much as the bottom 57 per cent - in other words, fewer than the 50 million richest people receive as much as the 2.7 billion poorest. Also the poorest 40 per cent of world population receive just 5 per cent of world income. Action to address climate change must be conducted in a way which does not amplify and ossify these global inequalities but rather helps to realise the development aspirations of current and future generations in developing countries.

Putting climate change and global inequality together, a new international development consensus should be forged around the notion of global sustainable development. If this replaced 
global integration as a central organising principle, it would provide the vision for a new long-wave of innovation and rising prosperity.

This consensus must be grounded in arguments that go beyond the moral ones which underpin the current MDG paradigm to articulate the mutual interests of both rich and developing countries in the economic development of the latter. It should also be based on a discourse of hope rather than a discourse of fear. Rich countries have an interest in economic development not simply to avoid the negative global spillover effects associated with widespread, grinding poverty. There is also a positive agenda which is rooted in the development of markets globally and the unlocking of the unrealised human and creative potential which exists in developing countries, as well as in the necessity of joint action to mitigate climate change effectively.

\subsection{Developing productive capacities as a new analytical and policy narrative}

The new development paradigm requires not only a new organising principle on which an international development consensus can be based but also a new analytical and policy narrative about how development can be promoted. In this regard, the idea that national and international policy should focus on developing productive capacities and the associated expansion of productive employment is particularly promising.

This approach has been elaborated and advocated in recent years within the context of UNCTAD's Least Developed Countries Reports (UNCTAD 2004, 2006, 2007). In this context, productive capacities are defined as 'the productive resources, entrepreneurial capabilities and production linkages which together determine the capacity of a country to produce goods and services and enable it to grow and develop' (UNCTAD 2006: 61). The core processes through which productive capacities develop are capital accumulation, technological progress and structural change. These are all closely linked so that technological progress cannot be understood in isolation from capital investment processes and both these processes have two-way links with structural change. Moreover, the development of productive capacities is closely related to the growth of demand.
The productive capacities approach is founded on heterodox growth theories. These do not adopt a production function approach which views 'the growing economy as an inflating balloon in which added factors of production and steady flows of technolgical change smoothly increase aggregate GDP' (Ocampo 2005: 8). Rather the growth process depends on the technological capabilities of economic agents and the institutional matrices in which they are embedded, the dynamics of production structures and the role of demand - what I have called elsewhere a 'structure-and-agency' approach to economic growth (Gore 2007).

This 'structure-and-agency' approach not only provides a better understanding of how economic growth occurs but also a better explanation of why different growth trajectories are more or less poverty-reducing. It also enables the adoption of poverty reduction policies which are not a separate add-on to existing policies but rather an integral aspect of the way in which economic growth is promoted (Gore 2007). This is not trickle-down economics. Rather, both growth and poverty trends are emergent properties of the way in which productive capacities are expanded. UNCTAD (2006) identifies some of the critical channels through which this occurs in the case of LDGs. Although it has not yet been done, this argument could be extended to the issue of environmental sustainability as this is also a matter of the way in which productive capacities are developed. That is to say, economic growth, poverty reduction and environmental sustainability can all be understood as emergent properties of the process of developing productive capacities. With this analytical framework, developing countries can be encouraged not to leave aside the issues of environmental sustainability until later and simply focus on economic growth now but rather be empowered to promote the development of productive capacities in a way which achieves economic growth, poverty reduction and sustainability objectives.

Implementing the productive capacities approach would require a new developmental state (UNCTAD 2009). This would be geared to facilitating access to, use of and the generation of knowledge as well as integrating with global production networks and value-chains, and it would seek to tap the energies of stakeholders 
and citizens through a genuinely participatory rather than authoritarian style of development governance. The development state model also would provide the basis for promoting the technological diffusion and acquisition necessary for the structural change to a low-carbon development trajectory.

\subsection{A new approach to international development cooperation}

The final element of the new development paradigm must be a new approach to international development cooperation. In this regard, the partnership approach, based on country ownership of national development strategies, is certainly the right way to go. It recognises that development aid - and development cooperation more broadly - is a relationship whose effectiveness depends on the practices of both parties. But the new paradigm must more seriously address the terms of development partnership, seeking to make them more balanced and equal. The Paris Declaration process has not adequately been able to address this issue thus far. It has become bogged down in the technical details of monitoring and evaluation, with the constant auditing of indicators having a counter-productive effect on outcomes. A new departure is thus required.

If one looks at the international aid regime in a long-term perspective, it is possible to see the current approach to achieving the MDGs as a kind of halfway house in a process of a global frame shift. In the 1950s and 1960s, 'national development means' were used to achieve 'national development goals'. These 'national development means' include national aid budgets in rich countries, government-to-government financial resource transfers and national plans, and the 'national development goals' were national economic development, employment expansion, rising living standards and national sovereignty. Within the current MDG paradigm, 'national development means' are used to achieve 'global development goals'. In the future, it is possible to envisage a shift towards an era in which 'global development means' are used to achieve 'global development goals'. In this vision, the MDGs could become social and economic rights which are guaranteed at a global level and not financed through national budgets but through innovative global sources of finance, such as taxes on global transactions.
There is still a need for country-to-country financial resource transfers. But these would be oriented towards discovering and releasing creative potential through sustainable development of productive capacities. This could best be achieved not through government-togovernment transfers, within the current new public management auditing approach but rather, there should be a new approach to aid which is concerned to leverage development finance through catalysing private sector initiatives (see, e.g. Cohen et al. 2005). This would necessarily be more experimental and risk-taking than current approaches to accounting aid effectiveness allow.

Finally, an important insight of the current partnership approach is the realisation that development and poverty reduction are not simply a matter of aid but also influenced by the nature of international regimes for trade, technology, finance and investment. A critical challenge for the coming era will be to inject a development dimension into the design of these international architectures. Experience with the Doha Development Agenda indicates how difficult this can be. Ensuring policy coherence among the different regimes, including aid regime, will also be critical. Attention must also extend to injecting a development dimension into the emerging climate change regime, the intellectual property rights regime and international migration regime. The last one is particularly serious as the globalisation of expectations is an inevitable feature of the instant communication age we are now living in. But owing to the highly unequal global development trajectory, there has been a globalisation of expectations without a globalisation of opportunity. This is a recipe for political instability.

\section{The future of poverty reduction}

Ideological innovation often occurs through transformations of the available normative vocabulary and thus, there is no reason to suppose that the idea of poverty reduction in general and the MDGs in particular do not have a future. In the long term, as suggested above, the MDGs may become the basis for global social and economic rights. However, in the mean time, there is still a need for a set of indicators which measures differences in wellbeing within global social space and the content of the MDGs as a set of targets should be revisited as such. All the work which has gone into building statistical networks to compare 
people around the world on the basis of the MDGs should also be reoriented within this wellbeing perspective. More effort should also be devoted towards specifying the eighth MDG Goal,

'Developing a Global Partnership for

Development' as the Targets of this Goal are weak. Relating elements of a genuine global partnership for development to wellbeing within developing countries will also require analytical innovation. A form of explanation, which I have called 'methodological nationalism' (Gore 1996) currently pervades poverty analysis and this should be replaced by what Townsend (1993) presciently called 'the international analysis of poverty'.

Although the MDGs can, in modified form, usefully live on, the argument of this article is

\section{Note}

* The views in this article are not necessarily those of UNCTAD.

\section{References}

Cohen, D.; Jacquet, P. and Reisen, H. (2005) 'Beyond "Grants Versus Loans": How to Use Debt for Development?', paper prepared for the AFD/EUDN international conference on 'Financing Development', Paris, 15 December

Ferguson, Niall (2009) 'The Crisis and How to Deal With It', New York Review of Books 56.10: 11 June

Gore, C.G. (2007) 'Which Growth Theory is Good for the Poor?', European Journal of Development Research 19.1: 30-48

Gore, C.G. (2005) 'National Development Strategies for Achieving the MDGs: A Comparison of the UN Millennium Project and World Bank Approach', Revue Economique et Sociale 4: 29-40

Gore, C.G. (2004) 'MDGs and PRSPs: Are Poor Countries Enmeshed in a Global-local Double Bind?', Global Social Policy 4.3: 277-83

Gore, C.G. (2003) 'Development Partnership for Escaping the Global Poverty Trap', Development Policy Journal 3: 107-26

Gore, C.G. (2000) 'The Rise and Fall of the Washington Consensus as a Paradigm for Developing Countries', World Development 28.5: 789-804

Gore, C.G. (1996) 'Methodological Nationalism and the Misunderstanding of East Asian Industrialization', European Journal of Development Research 8.1: 77-122 that the current MDG paradigm is no longer helpful. It is necessary now to build a new international development consensus around global sustainable development. Policies to promote poverty reduction and the achievement of a modified list of MDGs should also be embedded in future within a different policy approach based on more equal terms of development partnership and which recognises that the best way to achieve desirable social objectives is through the development of productive capacities. In the end this will be the most effective path for fulfilling 'the collective responsibility to uphold the principles of dignity, equality and equity at a global level', recognised in the Millennium Declaration.

Losch, B.; Freguin-Gresh, S. and Giordano, T. (2008) 'Structural Dimensions of Liberalization on Agriculture and Rural Development:

Background, Positioning and the Results of the First Phase', mimeo, World Bank

Milanovic, B. (2005) Worlds Apart: Measuring International and Global Inequality, Princeton: Princeton University Press

Nardin, T. (1983) Law, Morality and the Relations of States, Princeton: Princeton University Press

Ocampo, J.A. (2005) 'The Quest for Dynamic Efficiency: Structural Dynamics and Economic Growth in Developing Countries', in J.A. Ocampo (ed.), Beyond Reforms: Structural Dynamics and Macroeconomic Vulnerability, Stanford and Washington DC: Stanford Economics and Finance, Stanford University Press and World Bank

Pritchett, L. (2003) Who is Not Poor? Proposing a Higher International Standard for Poverty, Working Paper 33, Washington DC: Centre for Global Development

Townsend, P. (1993) The International Analysis of Poverty, Hemel Hempstead: Wheatsheaf

UNCTAD (2009) The Least Developed Countries Report 2009: The State and Development Governance, Geneva and New York: United Nations

UNCTAD (2008) The Least Developed Countries Report 2008: Growth, Poverty and the Terms of Development Partnership, Geneva and New York: United Nations 
UNGTAD (2007) The Least Developed Countries Report 2007: Knowledge, Technological Learning and Innovation, Geneva and New York: United Nations

UNCTAD (2006) The Least Developed Countries Report 2006: Developing Productive Capacities, Geneva and New York: United Nations

UNGTAD (2004) The Least Developed Countries Report 2004. Linking International Trade with
Poverty Reduction, Geneva and New York: United Nations

UNCTAD (2002) The Least Developed Countries Report 2002: Escaping the Poverty Trap, Geneva and New York: United Nations

UN (2000) The Millennium Declaration, New York: United Nations 